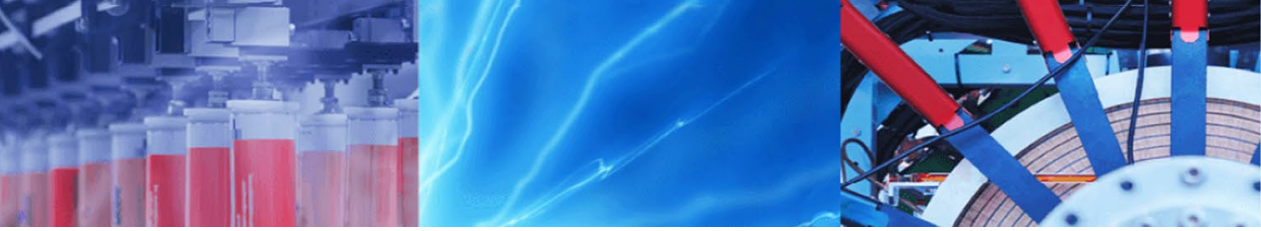

Research Article

\title{
Assessment of the bioclimatic conditions over some selected stations in Nigeria
}

\author{
I. A. Balogun ${ }^{1}$ A. A. Ntekop ${ }^{1,2} \cdot$ M. T. Daramola ${ }^{1}$ (I) \\ (c) Springer Nature Switzerland AG 2019
}

\begin{abstract}
This study seeks to assess the bioclimatic conditions of some selected stations in Nigeria from 1981 to 2010 using meteorological data input from the Nigerian Meteorological Agency (NIMET). The specific objectives were to analyze the spatiotemporal variability of the key weather parameters critical to bioclimatic conditions, evaluate the monthly and seasonal variation of the bioclimatic conditions and analyze the spatiotemporal variation of the human bioclimatic conditions over the area. The study applied the use of two bioclimatic indices, namely physiological equivalent temperature (PET) and Universal Thermal Climate Index (UTCI). PET was computed using the RayMan model, while UTCI was computed using the Bioklima model. The bioclimatic conditions were observed to vary seasonally as thermal stress levels particularly increased in the months of March to May and these months correspond to the pre-wet period of the year. The conditions, however, improved during the wet and dry periods. The early hours of the day (0600 Local Standard Time) were characterized mostly by no thermal stress conditions; however, the northern regions were cooler than the other parts of the country. The frequency of thermal stress categories for each station also revealed the threshold of the thermal stress condition over each station. The result from this study provides useful bioclimatic information applicable in the development of adaptive strategies and efficient planning with respect to the thermal environment.
\end{abstract}

Keywords Bioclimate $\cdot$ Nigeria $\cdot$ PET $\cdot$ Seasonal variation $\cdot$ Thermal stress $\cdot$ UTCI

\section{Introduction}

The understanding of the climate and bioclimate of any city is very vital as there is the evolving issue of urbanization and change in global climate. One of the major issues in the world today is the increase in global population particularly in the urban areas. This has various environmental consequences such as alteration of the local climate. Development of an area usually involves changes in the land cover and consequently, the climate of the area. Several studies have reported the impact of land use changes on the local climate and the thermal environment due to alteration of the land physical characteristics [1-4]. Uncontrolled and spontaneous urbanization with little or no regard for the thermal environment is an issue in most developing countries today. This has implication on the microclimate of an area, as meteorological parameters are altered. Modification of meteorological parameters alters the atmospheric condition of an environment. Parameters such as air temperature, relative humidity and wind speed have a direct impact on thermal comfort $[5,6]$ particularly outdoor comfort conditions. Alteration of climate within continuously urbanized areas may result in greater bioclimatic stress and medical issues [7]. The general well-being of individuals is affected considerably by the bioclimatic conditions [8]. The study of the effect of climate on the human body defines human bioclimatology.

\footnotetext{
$\triangle$ I. A. Balogun, iabalogun@futa.edu.ng; $\bowtie$ M.T. Daramola, daramolamt@futa.edu.ng| ${ }^{1}$ Department of Meteorology and Climate Science, School of Earth and Mineral Sciences, Federal University of Technology, Akure, Ondo State, Nigeria. ${ }^{2}$ Department of Weather Forecast Service, Nigerian Meteorological Agency, Abuja, Nigeria.
} 
The need for human thermal balance modeling resulted in the development of bioclimatic models, which are extensively employed in bioclimatic studies. Notable research has been done with the purpose of creating dependable and comprehensible index for thermal response evaluation of the human body to climatic conditions [9]; nevertheless, just physiological equivalent temperature (PET) and Universal Thermal Climate Index (UTCI) seem to fulfill the fundamental conditions [10]. Human bioclimatic study reports the effects of climatic parameters on the human body using these simple indices. The output of the indices is presented in values easily comprehensible by different individuals [11]. PET has been applied for studying the bioclimatic conditions in different parts of the world: Hungary [12], Nigeria [13], Iran [14, 15], Tanzania [16], Greece [17] and Serbia [18]. A number of studies have also applied UTCI globally such as over Saudi Arabia [19], Crete Island [8].

Thermal discomfort and stress levels information are important as this affects the effective function of people and also result in health challenges particularly for aged persons [19]. Knowledge and understanding of the bioclimatic situation help in effective preparedness and development of coping strategies. Analysis of the bioclimatic condition provides individuals with the required knowledge of the bioclimate, necessary for making policies and mitigation approaches to the extreme case as a result of climate change [8]. Adequate bioclimatic information is essential for effective planning and design of both indoor and outdoor environments [20-22]. Over the past decades, awareness has been drawn to the assessment of bioclimatic conditions with the change in climate and increased heat stress within cities [6,23-25]. Study has revealed that several neighborhoods in Africa have been affected by health stress particularly with an increase in urbanization [26]. Most developing counties are at high risk of increased heat stress as the rate of urbanization is not proportional to the social, economic and technological advancement $[27,28]$.

Studies on the bioclimatic conditions over Nigeria have been done; however, these studies are few. Some of the studies include Balogun and Balogun [29] that applied the use of simple indices, namely thermohygrometric index (THI), discomfort index (DI) and the relative strain index (RSI), for the examining the impact of urbanization on human bioclimatic conditions of the city of Akure. Musari et al. [30] described the periods caused by heat stress in some selected urban towns in five states of the north central region in Nigeria. Temperature-humidity index (THI) and wind chill index (WCl) were employed for the investigation over the five urban towns in north central region. Eludoyin [31] assessed the changes in the daytime physiological comfort of Nigeria using the effective temperature index (ETI), temperature-humidity index (THI) and relative strain index (RSI). Of the previous human bioclimatic studies over Nigeria, THI is the most commonly used index. No study has applied the use of UTCl in assessing the bioclimatic condition of Nigeria. This study, therefore, assesses the bioclimatic conditions over some selected stations in Nigeria using the PET and UTCI. The monthly, seasonal and spatial variation of the human bioclimate was examined as well as the frequency of occurrence of the thermal stress levels for each station.

\section{Study area, materials and methods}

For this research work, the study area includes nine selected stations within Nigeria. The stations are representative of three climatic zones according to the classification of Omotosho [32]; Guinea (coast $8^{\circ} \mathrm{N}$ ), Sudan $\left(8^{\circ} \mathrm{N}-11^{\circ} \mathrm{N}\right)$ and Sahel $\left(110 \mathrm{~N} 16^{\circ} \mathrm{N}\right)$.

The objective of this study is to assess the bioclimatic conditions of different time periods over different locations; therefore, monthly observed meteorological data of air temperature $\left({ }^{\circ} \mathrm{C}\right)$, wind speed $(\mathrm{m} / \mathrm{s})$, relative humidity $(\%)$ and solar radiation $\left(\mathrm{W} / \mathrm{m}^{2}\right)$ were obtained from the archives of the Nigerian Meteorological Agency (NIMET), Oshodi, Lagos. The data obtained were at 0600 and 1500 Local Standard Time (LST) over a period of thirty years (1981-2010). 0600 and 1500 LST represent two distinct periods of the day with varying atmospheric conditions, which helped to assess the thermal stress levels at varying conditions (Fig. 1).

To achieve the set objectives of this research, two bioclimatic models RayMan and Bioklima were employed to derive the physiological equivalent temperature (PET) and Universal Thermal Climate Index (UTCI), respectively. PET and $\mathrm{UTCl}$ are recognized as two of the most extensively utilized indices in outdoor thermal perception research [33].

As shown in Fig. 2, the meteorological data were used as input for the RayMan and Bioklima models. The data were first subject to quality control analysis which helps to identify missing data and outliners. The data were then inputted into the models. The models used in this study are user-friendly models which are easily usable by inputting the required weather data. The computation is done by the model, and the output is provided as text files. The data output provided in text files contains the values for the corresponding periods at the time intervals. The process of data input, computation and output was repeated for each station considered in this study. The data from both models were used in assessing the monthly variation of both PET and UTCI by averaging the values for each month over the thirty-year period. 
Fig. 1 Map of Nigeria showing the selected stations

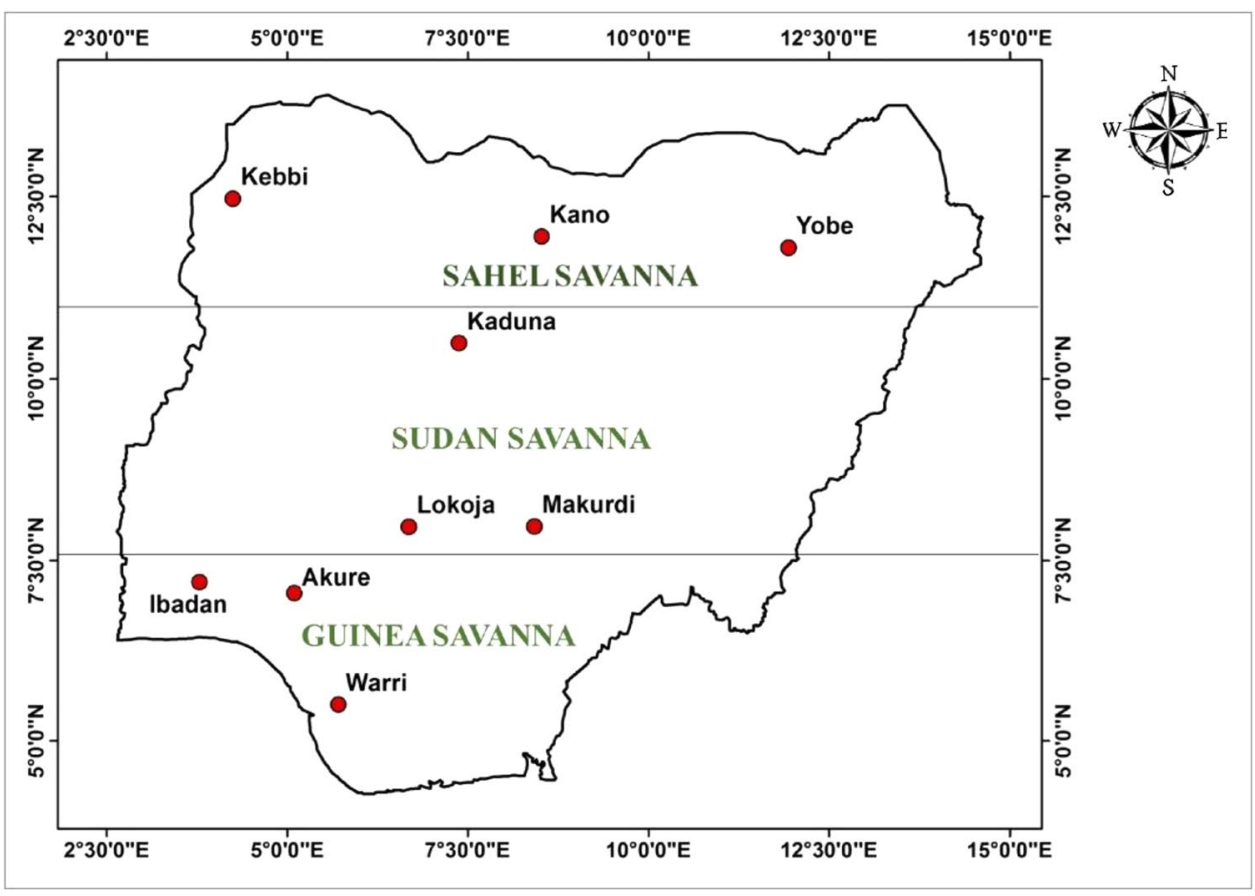

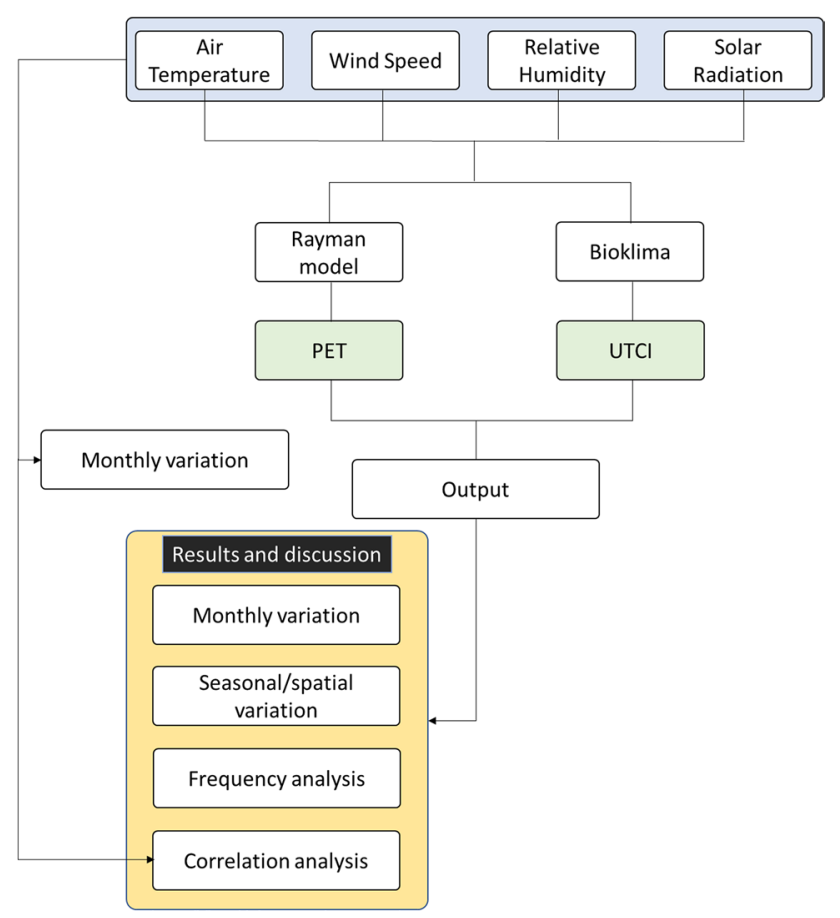

Fig. 2 Study framework

The mean monthly values were then plotted for each location at different time periods. In order to assess the seasonal variation of the indices, the months were classified into different categories. The seasonal classification of PET and UTCI was as follows: dry months (December, January and February), pre-wet months (March, April and
May), wet months (June, July, August and September) and pre-dry months (October and November). This classification was done for all the stations, and the variation between the classified groups representing the seasons was assessed. For the frequency analysis, the output of PET and UTCI was categorized into the respective thermal stress levels and the rate of occurrence of each level was derived. This was used to generate the bar plot containing the number of thermal stress level occurrences for each location at the two periods. The final analysis carried out in this study was the statistical relationship between the weather parameters and bioclimatic indices, PET and UTCI, using the Pearson correlation. Pearson correlation is a bivariate analysis commonly used in the assessment of the association between variables.

The computation of PET in RayMan model has its basis in the Munich Energy Balance Model for Individuals (MEMI):

$M+W+R+C+E_{\mathrm{D}}+E_{\mathrm{Re}}+E_{\mathrm{SW}}+S=0$

where $M=$ the metabolic rate (internal energy production), $W=$ the physical work output, $R=$ the net radiation of the body, $C=$ the convective heat flow, $E_{D}=$ the latent heat flow to evaporate water diffusing through the skin (imperceptible perspiration), $E_{\mathrm{Re}}=$ the sum of heat flows for heating and humidifying the inspired air, $E_{\mathrm{SW}}=$ the heat flow due to evaporation of sweat, and $S=$ the storage heat flow for heating or cooling the body mass.

PET has several advantages in assessing the human bioclimate of a region. It shows the actual effect of human sensation of climate and has application in hot as well as 
cold climates, and the output is given in degree Celsius $\left({ }^{\circ} \mathrm{C}\right)$, which is easily comprehensible [34].

RayMan model was developed at the Meteorological Institute, University of Freiburg $[35,36]$. The model applies meteorological parameters such as air temperature, relative humidity, cloud cover as input and then estimates the radiation flux within environmental configurations presenting the thermal perception as output $[35,37]$.

The other index used in this study is the UTCI, "expressed as an equivalent ambient temperature $\left({ }^{\circ} \mathrm{C}\right)$ of a reference environment providing the same physiological response of a reference person as the actual environment" [38]. UTCI is a more recent index based on a Fiala multi-node model of human thermoregulation [39]. UTCI was developed with the intention of creating a standard measure in outdoor human bioclimatic assessment [40]. When compared to other indices, UTCI has more sensitivity to little variations in temperature, solar radiation, humidity and wind speed and is seen to be an advantage in human-biometeorological assessments [38].

\section{Results and discussion}

\subsection{Climatic elements at 0600 and 1500 LST}

The monthly variation of air temperature, relative humidity and wind speed for 0600 and 1500 for the stations is presented in Fig. 3. It is shown that at $0600 \mathrm{~h}$, air temperatures are lowest in the Sahel savanna stations of the country, followed by the Sudan savanna station, and higher in the Guinea savanna stations. It is further observed that the Sahel and Sudan stations usually record their lowest air temperatures in the early hours in the months of December and January (during the Harmattan), but the Guinea savanna region of the country records its lowest early morning air temperatures between July and August. Air temperatures are generally low during the rainy season in this climatic belt of the country. Conversely, at $1500 \mathrm{~h}$, afternoon air temperatures rise and become highest in the Sahel and Sudan regions, while the Guinea stations now record lowest temperatures in the afternoon. At both
Fig. 3 Monthly variation of air temperature $\left({ }^{\circ} \mathrm{C}\right)$, relative humidity (\%) and wind speed $(\mathrm{m} / \mathrm{s})$
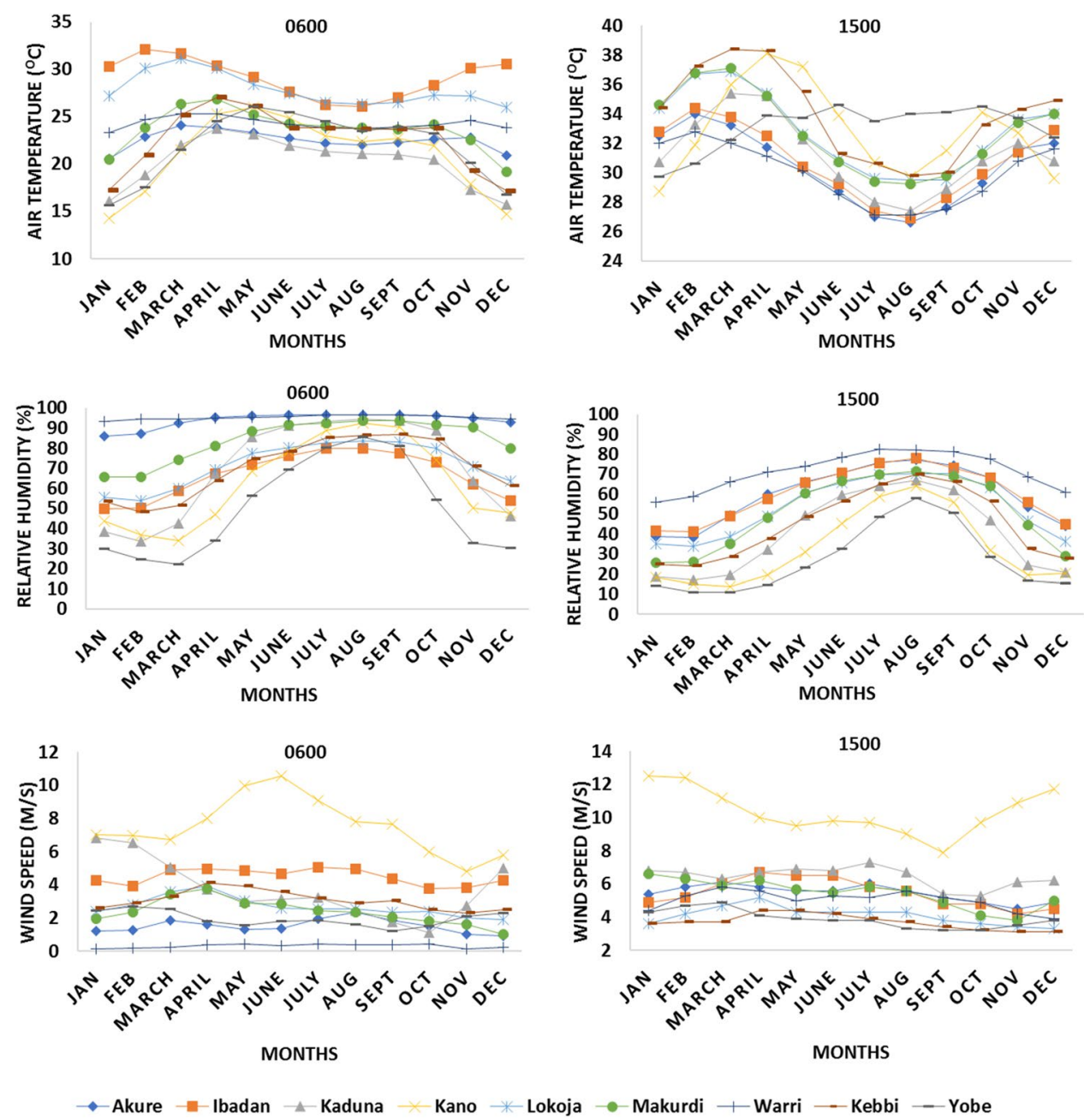

MONTHS 
0600 and $1500 \mathrm{~h}$, air temperatures are generally higher during the dry season, highest in February-March in the Guinea savanna but highest in March-April in the Sahel and Sudan savanna. However, for both synoptic hours, air temperature is generally lower during the rainy season at the Guinea stations, but at the Sahel and Sudan stations, air temperature is lower only at $0600 \mathrm{~h}$ during the dry seasons and lower at $1500 \mathrm{~h}$ during the wet season. This agrees with the study of Omonijo [41] that showed that the highest temperature occurs between the months of February and March, while the month of August has the least temperature. The least air temperature in August can be attributed to thick cloud and cooler soil conditions at this period of the year [42]. The wet months represent the rainy season for the states, a time of intense rainfall across the area. For the relative humidity, it is generally observed that relative humidity is usually higher during the wet season than during the dry season, which is around June to September. Furthermore, relative humidity is also observed to be higher in the early morning $0600 \mathrm{~h}$ than the $1500 \mathrm{~h}$. This rapid reduction observed in the afternoon hours is attributed to the heating influence of the solar radiation immediately after the sunrise. At 0600, there was no much variation between the values recorded over Warri and Akure, while the values over the other stations vary significantly. For both time periods, the dry periods were periods of low relative humidity, while the wet

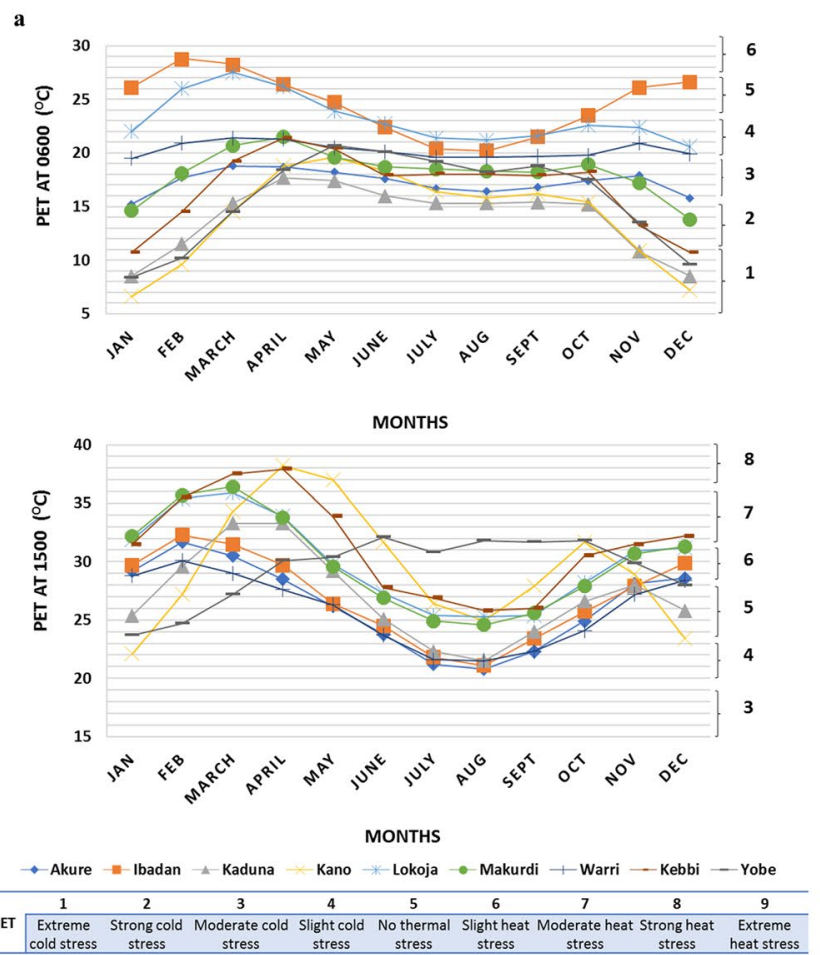

periods were periods of high relative humidity. This shows opposite distribution to air temperature. When comparing each station, Warri had the highest relative humidity values followed by lbadan and Akure. These stations are closest to the coast and thus the influence of the ocean as the trade winds from over the ocean blow in moist cool air. The monthly variation of wind speed shows that Kano has the highest wind speed all through the year.

\subsection{Bioclimatic conditions at 0600 and 1500 LST}

Figure 4 shows the monthly variation of bioclimatic conditions with respect to PET and UTCl estimates at 0600 and 1500 for the period of study at the stations. The monthly variation of UTCI reveals a similar pattern to that of PET at both synoptic hours considered, although the PET and UTCl estimates for both synoptic hours vary at different months for different stations. At $0600 \mathrm{~h}$, the least values of the bioclimatic comfort indices were observed in the Guinea savanna stations, Ibadan and Warri precisely, during the wet months (June to September), whereas stations in the Sudano-Sahelian region (Kano, Kaduna, Yobe, Kebbi and Makurdi) recorded its lowest values during the Harmattan period of dry season, precisely December and January. At $1500 \mathrm{~h}$, the values decreased at all the stations significantly around June to September except for Yobe. The high values indicate the period of increased
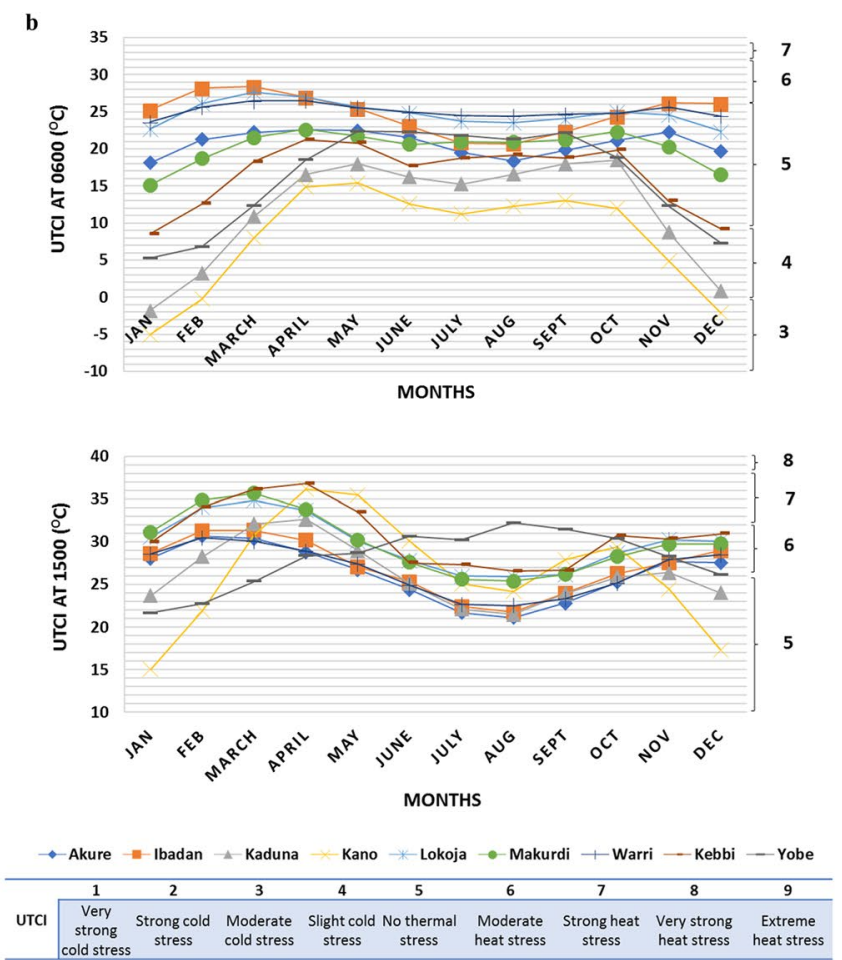

Fig. 4 a Monthly variation of PET $\left({ }^{\circ} \mathrm{C}\right)$ for the stations at 0600 and $1500 . \mathbf{b}$ Monthly variation of UTCI $\left({ }^{\circ} \mathrm{C}\right)$ for the stations at 0600 and 1500 
thermal stress across the stations. The highest PET values observed were in April in Kebbi and Kano at $38.2^{\circ} \mathrm{C}$, closely followed by Yobe with a record of $36.2^{\circ} \mathrm{C}$; all correspond to the "hot" and "strong heat stress" categories of the thermal perception and stress level presented in Table 1. PET values obtained in March for Kaduna, Makurdi and Lokoja are $33.8^{\circ} \mathrm{C}, 36.4^{\circ} \mathrm{C}$ and $35.9^{\circ} \mathrm{C}$, respectively; they also ranked at the "hot" and "strong heat stress" categories. It was observed that highest PET values in the Guinea savanna stations were recorded in February. Ibadan, Akure and Warri had $32.3^{\circ} \mathrm{C}, 32{ }^{\circ} \mathrm{C}$ and $30.1{ }^{\circ} \mathrm{C}$, respectively, all indicating moderate and slight heat stress categories. Though the monthly variation of the UTCI and PET reveals similar pattern, it was generally observed that UTCI has a low range of measured values compared to that of PET at both synoptic hours considered. For example, the UTCI underestimates the typical features of the Sahel savannah with respect to the nighttime cool conditions during the harmattan usually experienced in December to February. This is clearly shown as the records of Kaduna and Kano observed in Fig. 3 drop below 0 to -10 but range within the slightly cold/slight cold stress category in Table 1 . But a range of $0-10$ in PET indicates very cold thermal perception and extreme cold stress conditions. The general monthly variation revealed distinct thermal stress situations, and this agrees with previous related studies $[13,29$, 43]. Eludoyin and Adelekan [43] affirmed that the prevailing conditions during the dry months are hot, while during the wet months, the prevailing condition is cool in the study area. However, Balogun and Balogun [29] indicated in their microclimatic study over Akure that November and January were months with comfortable conditions in the region.

The spatial variation of PET and UTCI during the two distinct seasons in the study area, the dry and wet period conditions are shown in Figs. 4 and 5 respectively.
At $0600 \mathrm{~h}$ in the dry season, highest PET values were observed in the Guinea savanna, predominantly over the southwestern parts with values ranging between 20 and $27^{\circ} \mathrm{C}$, while the lowest PET values ranging from 7 to $11^{\circ} \mathrm{C}$ were observed over the northern region, mostly in the Sahel. Advancing from the southern parts toward the northern parts at 0600 , the values gradually decrease, indicating that the northern regions experience very cold thermal sensations and are extremely cold stressed in the early morning hours, while the southern parts have slight cold stress/no thermal stress. This is as a result of the peculiarities of the dry season conditions, also referred to as the Harmattan season. This period is characterized by cool, dry and dusty atmosphere, but more intense in the northern part of the country. The atmosphere is usually cold from nighttime to the early hours of the morning but unusually colder in the northern regions during the Harmattan, causing the Sahel and Sudan regions to experience cooler temperatures than their southern counterpart. That accounts for the thermal sensation levels of both regions at this period. This corresponds with the study of Eludoyin and Adelekan [39] over Nigeria that applied the thermohygrometric index (THI) for spatial analysis of bioclimatic conditions over Nigeria and noted that the mean THI during Harmattan period was higher over the southern region of Nigeria when compared to the northern region. Similar spatial distribution was observed with UTCI at 0600 , with the highest values of $20-26^{\circ} \mathrm{C}$ observed over in the Guinea savanna stations (Ibadan, Warri and Akure), closely followed by some Sudan savanna stations (Lokoja and Maiduguri). Kano (Sahel) had the lowest values (moderate cold stress), while Kaduna and Yobe experienced slight cold stress. At the $0600 \mathrm{~h}$ of the wet season, the PET shows that the entire climatic region experienced certain level of cold stress in the early morning hours. At $1500 \mathrm{~h}$ (PET) during the dry season, no thermal stress condition
Table 1 PET and UTCI range for different grades of thermal perception and stress level

\begin{tabular}{|c|c|c|c|}
\hline $\begin{array}{l}\text { PET classes for Nige- } \\
\text { ria }\left({ }^{\circ} \mathrm{C}\right)^{*}\end{array}$ & UTCI range $\left({ }^{\circ} \mathrm{C}\right)^{* *}$ & Thermal perception & Level of thermal stress \\
\hline \multirow[t]{2}{*}{$<11$} & $<-40$ & Very cold & Extreme cold stress \\
\hline & -40 to -27 & & Very strong cold stress \\
\hline $11-15$ & -27 to -13 & Cold & Strong cold stress \\
\hline $16-19$ & -13 to 0 & Cool & Moderate cold stress \\
\hline $20-23$ & $0-9$ & Slightly cool & Slight cold stress \\
\hline $24-27$ & $9-26$ & Neutral & No thermal stress \\
\hline $28-31$ & & Slightly warm & Slight heat stress \\
\hline $32-36$ & $26-32$ & Warm & Moderate heat stress \\
\hline \multirow[t]{2}{*}{$37-42$} & $32-38$ & Hot & Strong heat stress \\
\hline & $38-46$ & & Very strong heat stress \\
\hline$>42$ & $>46$ & Very hot & Extreme heat stress \\
\hline
\end{tabular}

*Omonijo and Matzarakis [13]; ** Blazejczyky et al. [39] 

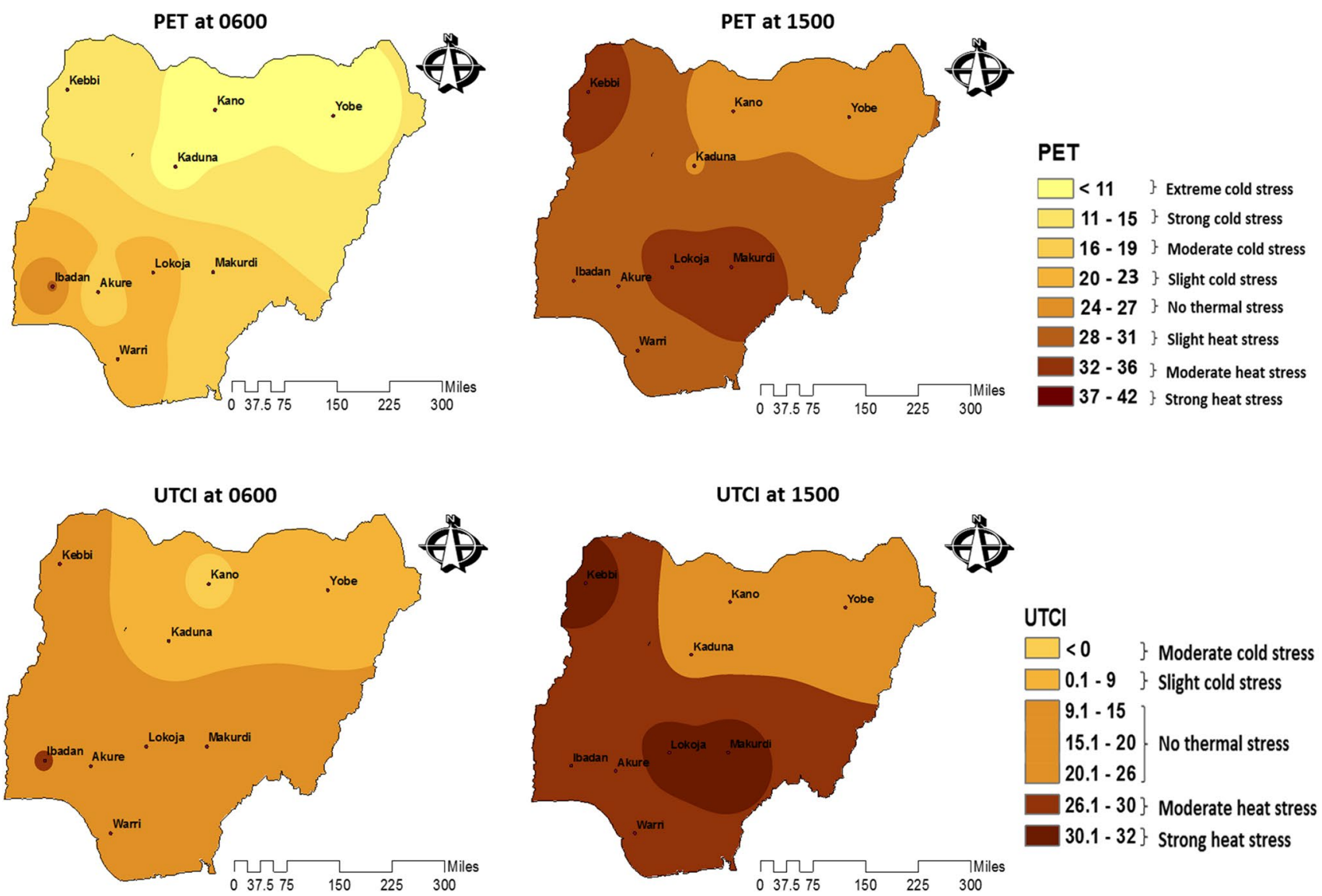

Fig. 5 Spatial variation of PET and UTCI for dry period (December, January and February)

was observed in the Sahel region except in Kebbi station that experienced moderate heat stress. Slight heat stress conditions dominated the Guinea savanna region. Generally, the maximum PET was recorded in Kebbi, Lokoja and Makurdi with values that ranged from 32 to $36^{\circ} \mathrm{C}$ (moderate heat stress), while Kano and Yobe had the least values of $24-25^{\circ} \mathrm{C}$ (no heat stress). The UTCl at 1500 during the dry season was similar to the spatial variation of PET at 1500 , with the highest values observed at Lokoja, Makurdi and Kebbi. These stations have the highest UTCI values ranging between 30.1 and $32{ }^{\circ} \mathrm{C}$, while Kaduna, Kano and Yobe have lowest values between 9.1 and $26^{\circ} \mathrm{C}$. Both indices generally reveal that Lokoja, Makurdi and Kebbi had the highest thermal discomfort level within this period. It was also noted that majority of the northern region was less thermally stressed, compared to the southern parts at both 0600 and 1500 during the dry season. However, the northern region usually experiences extreme cold stress which is not typical of the southern region in the early mornings of the dry season.

During the wet season, PET at 0600 reveals that the Sahel and Sudan regions fell within the moderate cold stress category, except at the northeastern station (Yobe) with slight cold stress. For UTCI, all the stations had the case of no thermal stress. PET at 1500 reveals slight cold stress over the Guinea stations as well as Kaduna (Sudan). Lokoja, Makurdi and Kebbi stations had cases of no thermal stress, while Kano and Yobe had slight and moderate heat stress conditions, respectively. For the UTCI at the afternoon hour of the wet season, all the Guinea stations fell under no thermal stress. Sudan stations except Kaduna had moderate heat stress conditions. The Sahel stations also had moderate heat stress conditions except for Yobe that recorded strong heat stress $(30.1-32)^{\circ} \mathrm{C}$. Both indices showed that the northwestern part of the country is the most thermally stressed region at $1500 \mathrm{~h}$ during the wet season. It was further observed that the spatial distribution patterns of PET and UTCI during the dry and wet seasons are quite similar, although there are marked differences in their thermal sensation levels. The spatial distribution of stress conditions from both indices also revealed differing distribution between the conditions at dry period and that of wet period. There are marked differences and distinct variations in the bioclimatic conditions of both synoptic hours at different seasons of the year. During the dry period, the northern part was cooler 
than the southern part, indicating less thermal stress at the northern part for 0600 and 1500 . However, during the wet season, the majority of the northern region was warmer than the southern part at 1500, indicating increased and higher thermal stress levels during this period (Fig. 6).

\subsection{Frequency of thermal stress classification}

In order to reveal the frequency of occurrence of each thermal sensation category for each station, the PET and UTCI values all through the year were categorized based on the thermal sensation levels and the frequency count of each category is shown in Fig. 7. The frequency plots highlight the range of the bioclimatic conditions as revealed by the indices over each station. The frequency analysis of PET at $0600 \mathrm{~h}$ showed that the highest level of thermal sensation category in Akure is within the strong cold stress category, with a speck of extreme cold condition. Ibadan, also a city in the Guinea savanna, is characterized and dominated with equal level of slight cold stress and no thermal stress categories, and minimal slight heat stress conditions. Warri is largely dominated by slight cold stress conditions with 11 counts and just a case of moderate cold stress. The stations examined in the Sudan savanna displayed notable varying degrees of thermal sensation categories. Kaduna was dominated by strong cold stress (5) conditions, followed by extreme cold stress (4) and low moderate cold stress (3) conditions. Lokoja had 8 cases of slight cold stress and 4 cases of no thermal stress category. Makurdi had 7 cases of moderate cold stress, 2 cases of strong cold stress and 3 cases of slight cold stress. The Sahelian stations exhibit similar thermal sensation categories (extreme, strong, moderate and slight) at the $0600 \mathrm{~h}$. The thermal sensation level in all the stations at $0600 \mathrm{~h}$ is dominated by moderate cold stress. It is also observed that all the stations in this savanna region experience equal frequency level of strong cold stress, but varying degrees of extreme cold and slight cold stress categories. UTCI frequency count of thermal perception at 0600 clearly showed that this period is a very comfortable period at all the stations. No thermal stress category characterizes the total period for Akure and Makurdi and also dominated other stations. Although there are few cases of moderate heat stress in the Guinea savanna, moderate heat, slight cold and moderate cold stress in Sudan savanna and moderate and slight cold stress categories in the Sahel
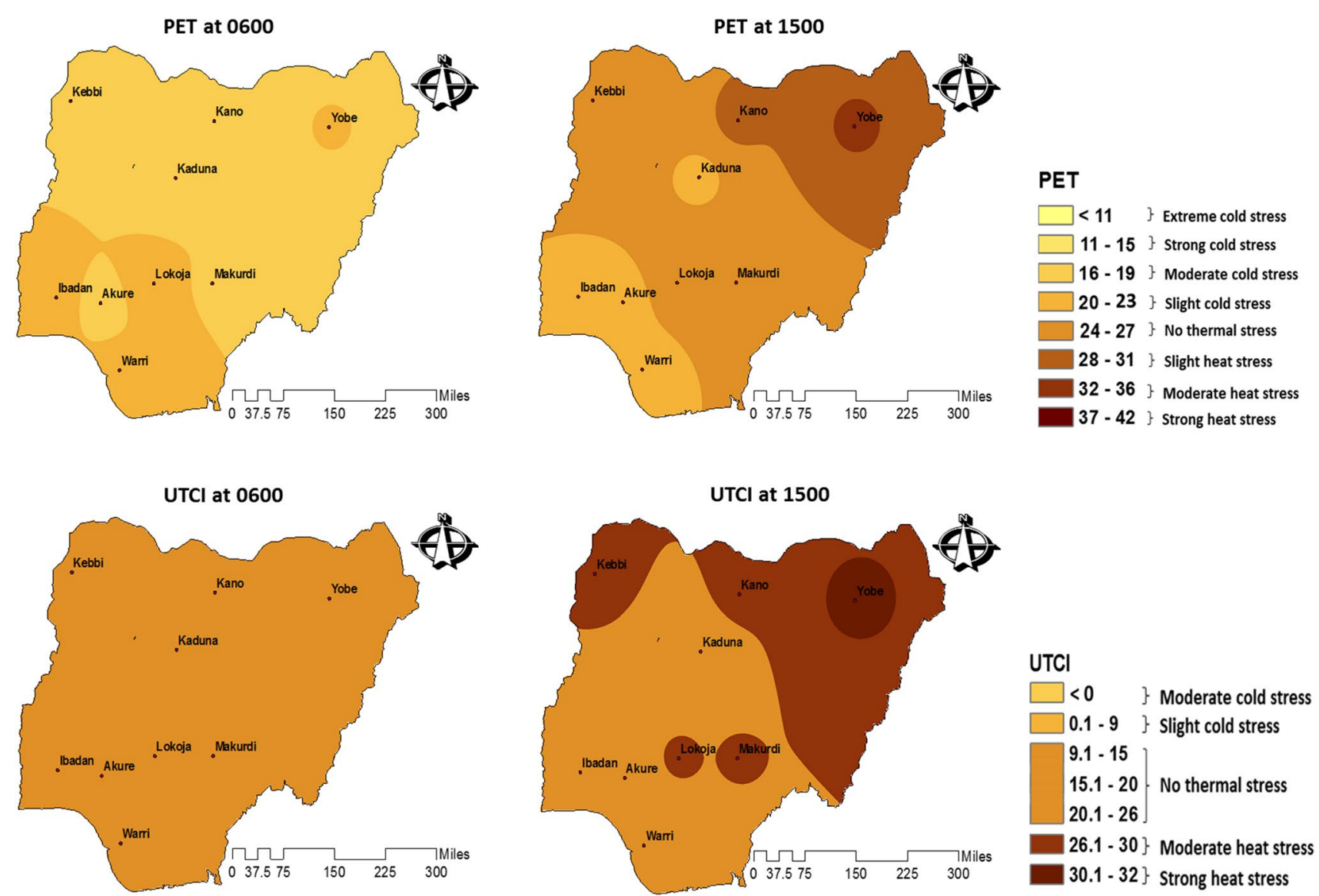

Fig. 6 Spatial variation of PET and UTCI for wet period (June to September) 
PET at 0600

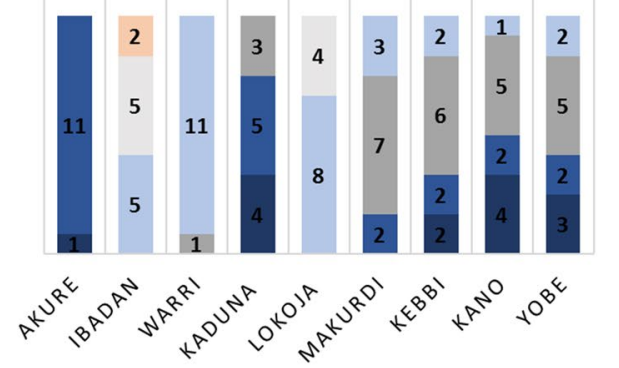

UTCI at 0600

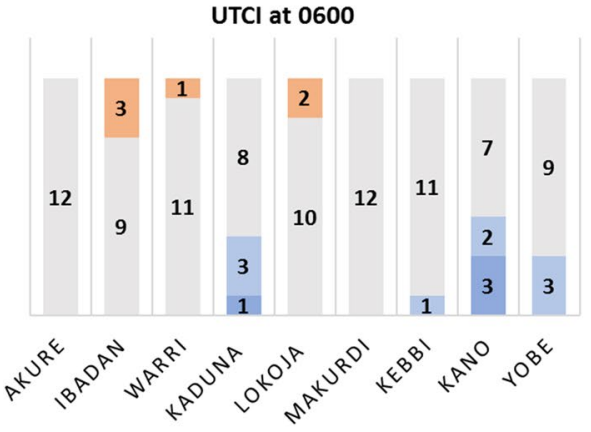

PET at 1500

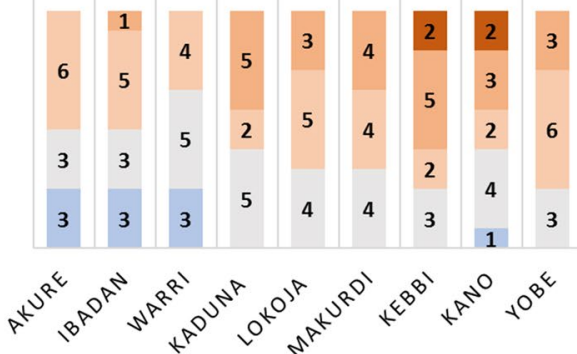

UTCl at 1500

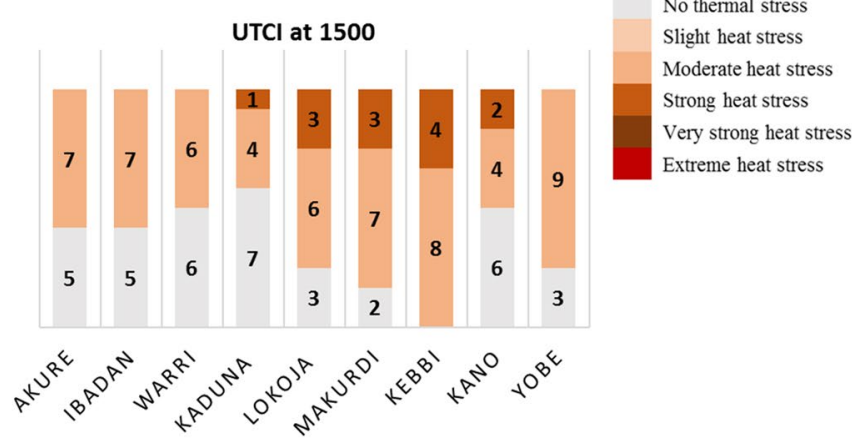

Fig. 7 Frequency count of thermal stress levels of PET and UTCI

region, no thermal stress conditions largely dominated the regions.

The frequency of PET classes at 1500 showed mixed classes and varying degrees of thermal sensation categories in all the savanna regions. Slight to moderate heat stress categories largely dominate the frequencies in all the stations except Warri which is a coastal city. Slight cold to slight heat stress conditions characterize the Guinea savanna region of the country. But, slight to moderate conditions characterize the Sudan savanna region, whereas slight to strong heat stress categories characterize the Sahelian region of the country. Strong heat stress category in this afternoon hour is only associated with the Sahelian station. UTCl at $1500 \mathrm{~h}$ showed that all stations experienced no thermal stress and moderate thermal stress categories, but strong thermal stress was peculiar to Sudan and Sahel savanna only.

The frequency count estimation reveals the threshold of the conditions at each station for both time periods. According to Roshan [44], thermal thresholds can be used in policy making, building technology and engineering in order to achieve better healthy living conditions. In general, the frequency count of PET at 0600 revealed that the stations in the Sahel (Kebbi, Kano and Yobe) recorded the highest number of thermal perception categories, while the Sudan stations (Kaduna and Makurdi) were characterized with three thermal perception categories and the Guinea stations (Akure and Warri) had two thermal perception categories. The exceptional cases are Ibadan and Lokoja that do not rank among their region. It was also observed that the range of thermal perception of the Sahelian stations was within slightly, strong and extreme cold stress categories. For UTCl, Kaduna and Kano had three categories, Ibadan, Warri, Lokoja, Kebbi and Yobe had two categories, while Akure and Makurdi had just one category. PET at 1500 showed that Kano had the highest number of thermal perception categories of five, lbadan and Kebbi both had four, while the other stations had three. For UTCI at 1500, Kaduna, Lokoja, Makurdi and Kano had three categories, while the other stations had two categories. The frequency of thermal stress categories represents the range of thermal stress levels obtained at different locations. This frequency varies differently spatially and also seasonally as noted in several studies $[14-16,45]$. It is also evident from the frequency plot that at $1500 \mathrm{LST}$, the thermal comfort condition deteriorated compared to the condition at 0600 . Studies have shown that the thermal conditions at 1500 LST are particularly influenced by the meteorological variables such as air temperature and the thermal comfort deteriorates significantly at this time $[29,31,45]$.

\subsection{Seasonal mean thermal perception categories of PET and UTCI}

Figure 8 shows the mean seasonal thermal perception categories for the stations across the savanna regions. 
It was revealed that the perception category of Akure at 0600 was moderate cold stress throughout the seasons for PET, while the UTCI showed no thermal stress condition. Ibadan experienced no thermal stress in dry, pre-wet and pre-dry periods, while slight cool stress was the condition during the wet season. UTCI, however, showed that dry and pre-wet periods were characterized by moderate heat stress, while no thermal stress occurred during the wet and pre-dry periods. Slight cool stress was observed for all the seasons over Warri according to PET, while UTCI categorized all the seasons as no thermal stress. Kaduna experienced extreme cold stress in dry season, strong cold stress in the pre-dry season and moderate cold stress in wet and pre-wet seasons for PET. Slight cold stress was the situation during the dry period, while the other seasons experienced no thermal stress based on UTCI. Over Lokoja, PET showed that slight cool stress was observed in dry, wet and pre-dry seasons, whereas no thermal stress was revealed in pre-wet season. No thermal stress was observed for all the stations except for pre-wet period with moderate heat stress for UTCI. In Makurdi, PET showed that moderate cold stress characterized all the seasons except in pre-wet where slight cold stress was noted. No thermal stress was the case for all the seasons according to UTCI. PET showed that over Kebbi, strong cold stress was experienced in dry and pre-dry seasons, whereas slight cold stress and moderate cold stress were observed in pre-wet and wet seasons, respectively. UTCl, however, showed no thermal stress all through the seasons. The condition over Yobe and Kano based on PET in dry season was extreme cold stress, while strong cold stress was experienced in pre-dry season. Moderate cold stress was noted in wet and pre-wet seasons. Based on UTCI, Kano experienced no thermal stress in the pre-wet and wet periods, while the dry and pre-dry periods were characterized by moderate and slight cold stress. Likewise, Yobe experienced no thermal stress in all the seasons except at dry season with slight cold stress condition.

The thermal condition at 1500 as estimated by PET showed that Akure experienced slight heat stress in dry season, pre-wet as well as pre-dry periods, whereas slight cool stress was noted in the wet season. Over Ibadan and Warri, slight heat stress was experienced in dry and prewet periods, while slight cold stress was experienced in wet season. Over Lokoja and Makurdi, moderate heat stress was experienced in dry season and pre-wet seasons, no thermal stress was found in wet season, and slight heat stress was observed in pre-dry season. Kaduna had the case of no thermal stress in dry season, moderate heat stress and slight heat stress were experienced in the two pre-seasons (wet and dry), while slight cool stress occurred in wet season. Moderate heat stress was experienced in the dry season and the pre-seasons over Kebbi, while the condition at wet season was no thermal stress. Kano and Yobe recorded no thermal stress and slight thermal stress in dry and pre-dry periods, respectively. UTCI at 1500 revealed that moderate heat stress characterized most of the periods at Akure, Ibadan and Warri except for the neutral conditions during the wet periods. The pre-wet periods at Lokoja, Makurdi, Kebbi and Kano were characterized by strong heat stress, while the pre-dry periods had moderate heat stress condition except for Kano.
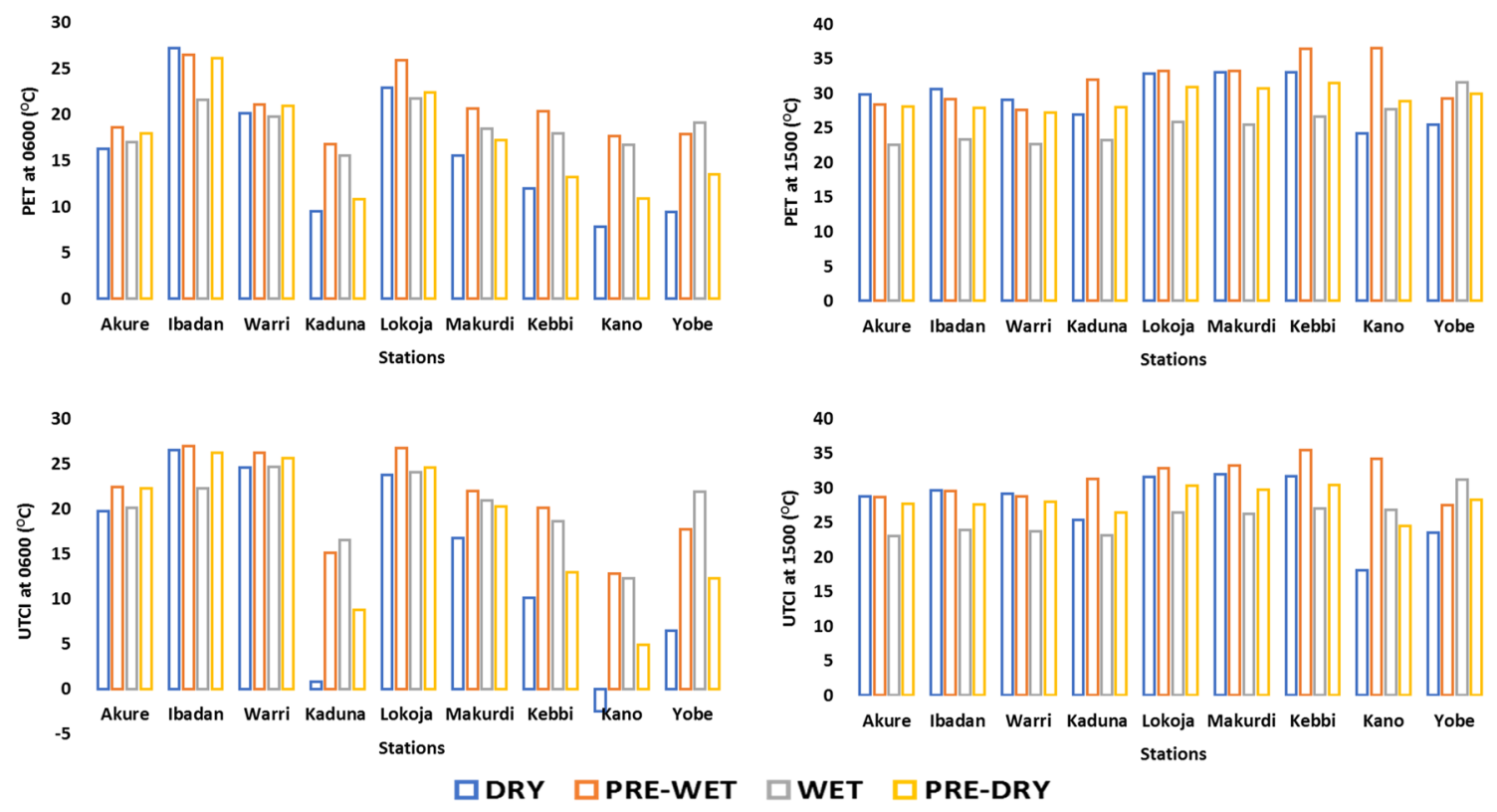

Fig. 8 Seasonal mean thermal perception for the stations 
The conditions at 0600 revealed that the highest values existed over Ibadan, Warri and Lokoja. Some of these conditions were, however, neutral conditions characterized by no thermal stress. Kaduna, Kano and Yobe had the coolest conditions during the dry season. At 1500, the highest values were over Lokoja, Makurdi and Kebbi during the dry season. During the pre-wet period, Kebbi and Kano had the highest values, indicating the warmest stations and thereby the most thermally stressed stations at this period. During the wet season, Yobe was the highest with moderate heat stress condition. For the predry period, Lokoja, Makurdi and Kebbi were the warmest stations with the highest stress levels. The thermal stress condition has been observed to vary seasonally in other studies across different locations in Nigeria [13, 45].

Combining the stations within each climatic zone, the seasonal mean PET and UTCI were also derived for the zones indicating the prevailing conditions per season (Fig. 9). The condition at $0600 \mathrm{~h}$ in all the seasons clearly showed that thermal stress level is highest in the Guinea savanna region, followed by Sudan and then Sahel regions. At 1500 synoptic hour, the conditions vary within the different seasons. The Sudan region is the most stressed at the dry, pre-wet and predry seasons. During the wet season, the Sahel region is observed to be the most thermally stressed among the climatic zones. Although bioclimatic conditions during the wet season became less stressful compared to the other seasons in other regions, both PET and UTCI results indicated that the Sahel region maintained slight heat stress and moderate heat stress conditions.

The general seasonal mean thermal stress level over Guinea showed that the transition periods (pre-wet and pre-dry) are the most thermally stressed periods. This was also observed in the study of the thermal comfort condition over locations in southwest Nigeria according to Njoku and Daramola [45]. The transition to wet period which corresponds to the pre-wet period in this study had the highest thermal comfort deterioration.

\subsection{Relationship between bioclimatic indices and meteorological parameters}

In order to assess the relative contributions of each meteorological parameter to the estimated thermal indices, correlation analyses between thermal indices and meteorological parameters were carried out. This reveals the meteorological parameters with the greatest or least influence on thermal conditions of each zone. Table 2 shows the correlation between of PET and UTCI against each meteorological parameter for each of the climatic zones. The statistics of PET and air temperature show strong positive correlation with values of $0.98,0.99$ and 0.93 for Guinea, Sudan and Sahel zones, respectively. The correlations of PET and relative humidity were negative for Guinea and Sudan zones with values of -0.47 and -0.50 but positive over the Sahel zone at 0.31. Wind speed and PET had negative correlations of $-0.30,-0.44$ and -0.71 for Guinea, Sudan and Sahel, respectively. The correlations
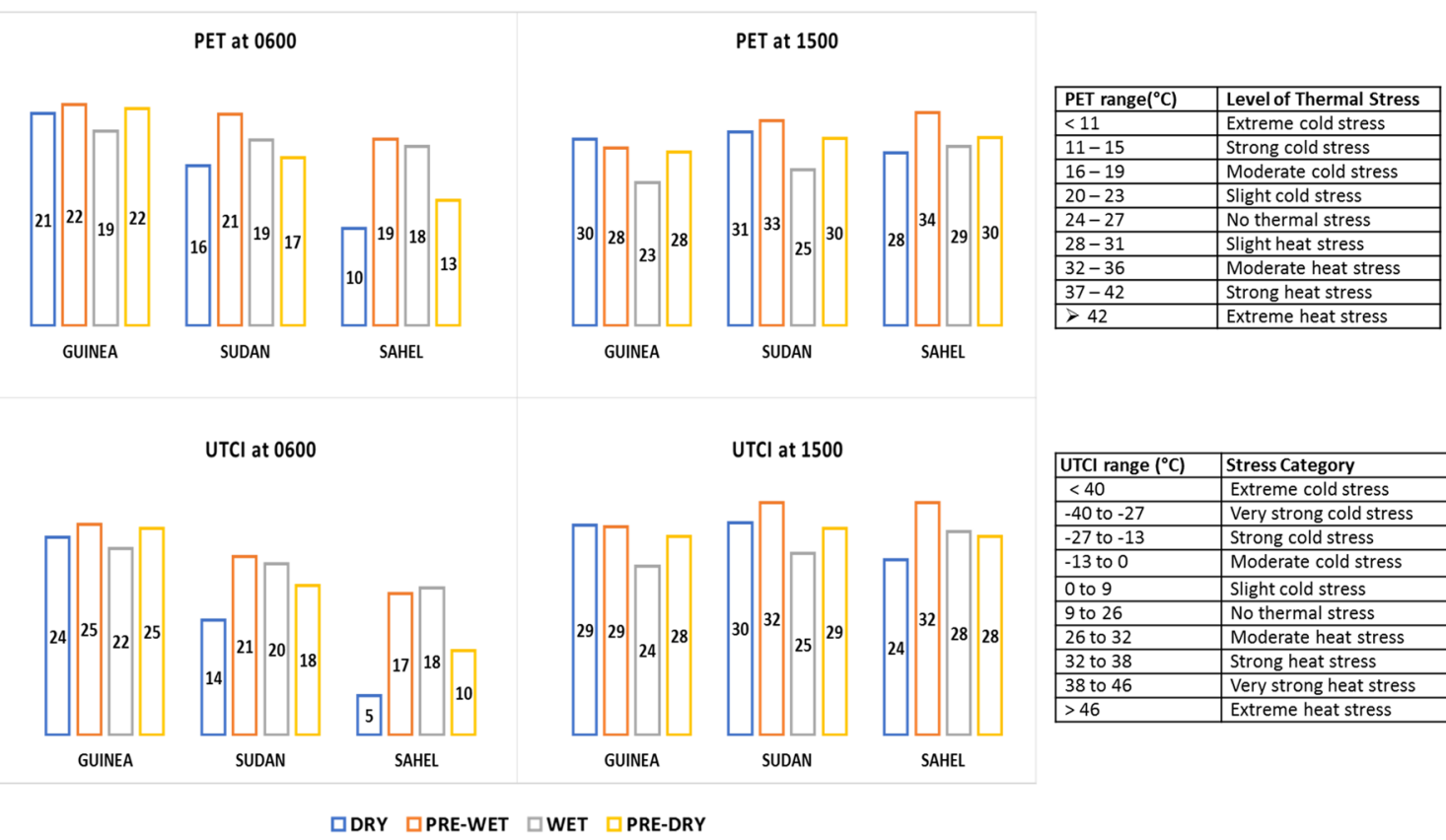

$>42$

Extreme heat stress

\begin{tabular}{|l|l|}
\hline UTCI range $\left({ }^{\circ} \mathrm{C}\right)$ & Stress Category \\
\hline$<40$ & Extreme cold stress \\
\hline-40 to -27 & Very strong cold stress \\
\hline-27 to -13 & Strong cold stress \\
\hline-13 to 0 & Moderate cold stress \\
\hline 0 to 9 & Slight cold stress \\
\hline 9 to 26 & No thermal stress \\
\hline 26 to 32 & Moderate heat stress \\
\hline 32 to 38 & Strong heat stress \\
\hline 38 to 46 & Very strong heat stress \\
\hline$>46$ & Extreme heat stress \\
\hline
\end{tabular}

DDRY $\square$ PRE-WET $\square$ WET $\square$ PRE-DRY

Fig. 9 Seasonal mean thermal perception categories for Guinea, Sudan savanna and Sahel 
Table 2 Correlation between bioclimatic indices and meteorological variables

\begin{tabular}{lccc}
\hline & Guinea & Sudan & Sahel \\
\hline PET & & & \\
Air temperature & 0.98 & 0.99 & 0.93 \\
Relative humidity & -0.47 & -0.5 & 0.31 \\
Wind speed & -0.3 & -0.44 & -0.71 \\
Vapor pressure & 0.07 & 0.21 & 0.64 \\
Mean radiant temperature & 0.98 & 0.99 & 0.99 \\
UTCl & & & \\
Air temperature & 0.91 & 0.96 & 0.9 \\
Relative humidity & -0.14 & -0.33 & 0.17 \\
Wind speed & -0.14 & -0.43 & -0.64 \\
Vapor pressure & 0.41 & 0.38 & 0.52 \\
Mean radiant temperature & 0.92 & 0.97 & 0.91 \\
\hline
\end{tabular}

of PET against vapor pressure for the zones were all positive with a very weak correlation for Guinea and Sudan. Mean radiant temperature (Tmrt) had very strong positive correlation with PET with values of $0.98,0.99$ and 0.99 for Guinea, Sudan and Sahel zones, respectively. The correlations of UTCl against meteorological parameter were similar to those of PET. Air temperature and UTCI had strong correlations that ranged between 0.89 and 0.96 in all the zones. Relative humidity and PET had negative correlation values of -0.14 and 0.33 in Guinea and Sudan but a positive correlation of 0.31 in the Sahel. Correlations of $\mathrm{UTCl}$ and wind speed were negative and ranged between -0.143 and -0.637 . The correlations of UTCI with vapor pressure and the Tmrt were positive in all of the climatic zones, but UTCI with Tmrt shows the strongest positive correlations in all the zones. The correlations show that air temperature and Tmrt have more influence on thermal comfort of each zone than other meteorological parameters. The strong positive correlations indicate that there is a direct relationship between temperature and thermal discomfort; therefore, periods of high temperature have high tendencies of being accompanied with high thermal discomfort, as well as periods of very low temperature associated with discomfort relating to cold stress. A direct relationship is observed between relative humidity and the bioclimatic indices in the Sahel region only, but indirect relationship exists in the Sudan and Guinea savanna regions. This symbolizes the different roles of relative humidity in the thermal comfort of the different regions. The negative correlations between thermal indices and wind speed indicate inverse relationships. Higher negative correlation with the thermal indices is observed in the Sahel. The influence of wind speed on the comfort condition in the Sahel is greater than in other regions, but the least in the Guinea. Vapor pressure is also observed to have a significant role in shaping the thermal comfort conditions in the Sahel region compared to others.

\section{Conclusion}

The bioclimatic conditions of nine stations representative of the three climatic zones in Nigeria, namely Guinea, Sudan and Sahel, were assessed in this study. The result from this study revealed seasonal and spatial variations in the thermal perceptions and stress level across the study area. Thermal stress levels were lower at 0600 LST compared to 1500 LST. Thermal stress levels were also observed to be higher at the pre-wet periods and lower in wet season. The southern region was less thermally comfortable in comparison with the northern region during the dry season at both 0600 and 1500 , but during the wet period, the northern region was less thermally comfortable than the southern region at 1500 . This reveals that the seasonal variation of the comfort conditions varies spatially at different time periods and over different climatic zones. This study has shown that bioclimatic conditions may vary with respect to individual stations and not largely the climatic zones. Some individual stations had dissimilar conditions with those stations within the same zones. This could be linked to the zonal classification adopted in the study, noting that some stations may have more distinct climate than others even within the same climatic zone. Akure, for example, had a similar bioclimatic condition with some stations in the northern part, so also Lokoja and Makurdi had similar variation with that of Kebbi for some periods. Air temperature and mean radiant temperature (Tmrt) are observed to be the highest contributor to thermal conditions in all the climatic zones, having shown very high correlation coefficients. It has revealed that periods of high temperatures are likely to be accompanied by thermal discomfort in the zones. This calls for concern considering that as the global mean temperature rises, temperature is also increasing at the regional level [46]. With the increase in mean temperature, thermal discomfort may increase in each zone. There is, therefore, the need for bioclimatic comfort modeling at local and regional scales. Bioclimatic information is essential for efficient planning and mitigation of intense thermal conditions which result in increased thermal stress levels. Likewise, sectors such as health and tourism will also benefit from the information provided in this study. The seasonal analysis, for example, is essential in tourism as tourists can identify the suitable periods of the year for visits. This study therefore recommends improved simulation of bioclimatic conditions over the region, particularly for future years. This will provide essential information applicable in the development of mitigation measures that can be adopted by the health, 
tourism and urban planning sectors. Identifying the thermal stress hot spots and its variation is crucial in the development of suitable approaches in an effort to mitigate the possible increase in thermal discomfort conditions. This will help foster strategies required in planning and designing healthy environments. This study also recommends the incorporation of urban green zones into city plans. The presence of vegetation cover such as urban parks has been identified as an approach for mitigating increased thermal stress conditions due to the cooling effect parks play on the thermal environment [47-50]. Incorporating urban green zones into city planning is an effective proactive measure that could be applied within the cities. Finally, this study calls for attention to be drawn toward improved climatological data collection by the deployment of more meteorological observation stations within different states and towns. This will help in the acquisition of the required data input for bioclimatological model simulations and thus provision of adequate bioclimatological information.

\section{Compliance with ethical standards}

Conflict of interest The authors declare that there is no conflict of interest regarding the publication of this paper.

\section{References}

1. Ishola KA, Okogbue EC, Adeyeri OE (2016) A quantitative assessment of surface urban heat islands using satellite multitemporal data over Abeokuta, Nigeria. Int J Atmos Sci. https://doi. org/10.1155/2016/3170789

2. Daramola MT, Eresanya EO (2017) Land surface temperature analysis over Akure. J Environ Earth Sci 7(5):97-105

3. Ogunjobi KO, Daramola MT, Akinsanola AA (2018) Estimation of surface energy fluxes from remotely sensed data over Akure, Nigeria. Spat Inf Res 26(1):77-89. https://doi.org/10.1007/s4132 4-017-0149-8

4. Daramola MT, Eresanya EO, Ishola KA (2018) Assessment of the thermal response of variations in land surface around an urban area. Model Earth Syst Environ. https://doi.org/10.1007/s4080 8-018-0463-8

5. Matzarakis A, Mayer H, Iziomon M (1999) Applications of a universal thermal index: physiological equivalent temperature. Int J Biometeorol 43:76-84

6. Nikolopoulou M, Baker N, Steemers K (2001) Thermal comfort in outdoor urban spaces: understanding the human parameter. Sol Energy 70:227-235

7. Gulyas A (2009) Human bioclimatic assessments at different scales. Ph.D. Thesis. University of Szeged Earth Science Graduate School

8. Bleta A, Nastos PT, Matzarakis A (2014) Assessment of bioclimatic conditions on Crete Island, Greece. Reg Environ Change 14:1967-1981. https://doi.org/10.1007/s10113-013-0530-7

9. d'Ambrosio Alfano FR, Palella BI, Riccio G (2011) Thermal environment assessment reliability using temperature-humidity indices, Ind Health 49:95-106
10. Nastos PT, Matzarakis A (2013) Human bioclimatic conditions, trends, and variability in the Athens University Campus, Greece. Adv Meteorol. https://doi.org/10.1155/2013/976510

11. de Freitas CR (2001) Theory, concepts and methods in climate tourism research. In: A Matzarakis, CR de Freitas (eds) Proceedings of the first international workshop on climate, tourism and recreation. International Society of Biometeorology, Commission on Climate Tourism and Recreation, pp 3-20

12. Gulyas A, Unger J, Matzarakis A (2006) Assessment of the microclimatic and human comfort Conditions in a complex urban environment: modelling and measurements. Build Environ 41:1713-1722

13. Omonijo AG, Matzarakis A (2011) Climate and bioclimate analysis of Ondo State. Meteorol Z 20:531-539. https://doi. org/10.1127/0941-2948/2011/0268

14. Daneshvar MRM, Bagherzadeh A, Tavousi T (2013) Assessment of bioclimatic comfort conditions based on physiologically equivalent temperature (PET) using the RayMan model in Iran. Cent Eur J Geosci 5(1):53-60

15. Esmaili R, Ghalhari F (2014) An assessment of bioclimatic conditions for tourists: case study of Mashhad, Iran. Atmos Clim Sci 4:137-146

16. Ndetto EL, Matzarakis A (2013) Basic analysis of climate and urban bioclimate of Dar es Salaam, Tanzania. Theor Appl Climatol 114:213. https://doi.org/10.1007/s00704-012-0828-2

17. Giannaros TM, Melas D, Daglis IA, Keramitsoglou I (2014) Development of an operational modelling system for urban heat islands: an application to Athens, Greece. Nat Hazards Earth Syst Sci 14:347-358

18. Basarin B, Kržič A, Lazić L et al (2014) Evaluation of bioclimate conditions in two special nature reserves in Vojvodina (Northern Serbia). Carpath J Earth Environ Sci 9:93-108

19. Abdel-Ghany AM, Al-Helal IM, Shady MR (2013) Human thermal comfort and heat stress in an outdoor urban arid environment: a case study. Adv Meteorol 187(10):693541

20. Cetin M (2015) Determining the bioclimatic comfort in Kastamonu City. Environ Monit Assess 187:640

21. Cetin M, Adiguzel F, Kaya O, Sahap A (2016) Mapping of bioclimatic comfort for potential planning using GIS in Aydin. Environ Dev Sustain. https://doi.org/10.1007/s10668-016-9885-5

22. Cetin M (2016) Determination of bioclimatic comfort areas in landscape planning: a case study of Cide coastline. Turkish J Agric Food Sci Technol 4(9):800-804

23. Swaid H, Bar-El M, Hoffman ME (1993) A bioclimatic design methodology for urban outdoor spaces. Theor Appl Climatol 48:49-61

24. Givoni $B$, Noguchi $M$, Saaroni $H$, Pochter $O$, Yaacov $Y$, Feller $N$, Becker S (2003) Outdoor comfort research issues. Energy Build 35:77-86

25. Spagnolo J, de Dear R (2003) A field study of thermal comfort in outdoor and semi-outdoor environments in subtropical Sydney Australia. Build Environ 38:721-738

26. Boko M, Niang I, Nyong A et al (2007) Africa: climate change 2007: impacts, adaptation and vulnerability. Contribution of Working Group II. In: Canziani OF, Parry ML, Palutikof JP, van der Linden PJ, Hanson CE (eds) 4th assessment report of the intergovernmental panel on climate change. Cambridge University Press, Cambridge, pp 433-467

27. UNFPA (2007) The state of world population 2007: unleashing the potential of urban growth. Fund United Nations Population, New York, p 32

28. Akinbode OM, Eludoyin AO, Fashae OA (2008) Temperature and relative humidity distributions in a medium-size administrative town in southwest Nigeria. J Environ Manag 87:95-105 
29. Balogun IA, Balogun AA (2014) Urban heat island and bioclimatological conditions in a hot-humid tropical city: the example of Akure, Nigeria. J Geograph Soc Berlin 145:1-2

30. Musari AA, Sojobi OA, Abatan OA, Egunjobi Al (2015) An estimate of thermal comfort in north-central region of Nigeria. IOSR J Appl Phys 7(1):60-66

31. Eludoyin OM (2014) A perspective of the diurnal aspect of thermal comfort in Nigeria. Atmos Climate Sci 4:696-709. https:// doi.org/10.4236/acs.2014.44063

32. Omotosho JB (1985) The separate contributions of line squalls, thunderstorms, and the monsoon to the total rainfall in Nigeria. J Climatol 5:543-552

33. Potchter O, Cohen P, Lin T-P, Matzarakis A (2018) Outdoor human thermal perception in various climates: a comprehensive review of approaches, methods and quantification. Sci Total Environ 631-632:390-406

34. Deb C, Ramachandraiah A (2010) The significance of physiological equivalent temperature (PET) in outdoor thermal comfort studies. Int J Eng Sci Technol 2(7):2825-2828

35. Matzarakis A, Rutz F, Mayer H (2007) Modelling radiation fluxes in simple and complex environments-application of the RayMan model. Int J Biometeorol 51:323-334. https://doi. org/10.1007/s00484-006-0061-8

36. Matzarakis A, Rutz F, Mayer $\mathrm{H}$ (2010) Modelling radiation fluxes in simple and complex environments-basics of the RayMan model. Int J Biometeorol 54:131-139

37. Thorsson S, Lindqvist M, Lindqvist S (2004) Thermal bioclimatic conditions and patterns of behaviour in an urban park in Göteborg, Sweden. Int J Biometeorol 48(3):149-156

38. Blazejczyky K, Epstein Y, Jendritzky G, Staiger H, Tinz B (2012) Comparison of UTCl to selected thermal indices. Int J Biometeorol 56(3):515-535. https://doi.org/10.1007/s00484-011-0453-2

39. Błażejczyky K, Jendritzky G, Bröde P, Fiala D, Havenith G, Epstein Y, Psikuta A, Kampmann B (2013) An introduction to the Universal Thermal Climate Index (UTCI). Geogr Pol 86(1):5-10

40. Jendritzky G, de Dear R, Havenith G (2012) UTCl—why another thermal index? Int J Biometeorol 56:421-428

41. Omonijo AG (2017) Assessing seasonal variations in urban thermal comfort and potential health risks using physiologically equivalent temperature: a case of Ibadan, Nigeria. Urban Clim. https://doi.org/10.1016/j.uclim.2017.05.006

42. Adefisan EA, Gbuyiro SO, Omotosho JB (2007) Development of irrigation requirements and water scheduling model for West Africa. Agric J 2:577-582

43. Eludoyin OM, Adelekan IO (2013) The physiologic climate of Nigeria. Int J Biometeorol 57:241-264

44. Roshan GhR, Ghanghermeh AA, Attia S (2017) Determining new threshold temperatures for cooling and heating. Degree day index of different climatic zones of Iran. Renew Energy 101:156-167

45. Njoku CA, Daramola MT (2019) Human outdoor thermal comfort assessment in a tropical region: a case study. Earth Syst Environ 3:29-42. https://doi.org/10.1007/s41748-019-00090-4

46. Daramola MT, Eresanya EO, Erhabor SC (2017) Analysis of rainfall and temperature over climatic. Zones in Nigeria. J Geogr Environ Earth Sci Int 11:1-14. https://doi.org/10.9734/JGEES I/2017/35304

47. Balogun IA, Daramola MT (2018) The impact of urban green areas on the surface thermal environment of a tropical city: a case study of Ibadan, Nigeria. Spat Inf Res 1:1. https://doi. org/10.1007/s41324-018-0219-6

48. Morakinyo TE, Lau KK-L, Ren C, Ng E (2018) Performance of Hong Kong's common trees species for outdoor temperature regulation, thermal comfort and energy saving. Build Environ 137:157-170. https://doi.org/10.1016/j.buildenv.2018.04.012

49. Feyisa GL, Dons K, Meilby H (2014) Efficiency of parks in mitigating urban heat island effect: an example from Addis Ababa. Landsc Urban Plan 123:87-95. https://doi.org/10.1016/j.landu rbplan.2013.12.008

50. Cetin M (2015) Using GIS analysis to assess urban green space in terms of accessibility: case study in Kutahya. Int J Sustain Dev World Ecol 22(5):420-424

Publisher's Note Springer Nature remains neutral with regard to jurisdictional claims in published maps and institutional affiliations. 